\title{
Exosomes Derived from Human Bone Marrow Mesenchymal Stem Cells Promote Tumor Growth Through Hedgehog Signaling Pathway
}

\author{
Jin Qja,b,c Yali Zhou ${ }^{\mathrm{b}}$ Zuoyi Jiao ${ }^{\mathrm{b}}$ Xu Wang ${ }^{\mathrm{c}}$ Yang Zhao ${ }^{\mathrm{b}}$ Yangbin Li ${ }^{\mathrm{b}}$ \\ Huijuan Chen ${ }^{b}$ Luxi Yang ${ }^{b}$ Hongwen Zhu ${ }^{b}$ Yumin Liab
}

aThe Second Hospital of Lanzhou University, Lanzhou, Gansu, China, 'Key Laboratory of Digestive System Tumors of Gansu Province, 'Key Laboratory of Orthopedics of Gansu Province, Lanzhou, China

\section{Key Words}

Exosome • Mesenchymal stem cell • MG63 • SGC7901 • Hedgehog signaling pathway

\begin{abstract}
Background/Aims: Mesenchymal stem/stromal cells (MSCs) are known to home to sites of tumor microenvironments where they participate in the formation of the tumor microenvironment and to interplay with tumor cells. However, the potential functional effects of MSCs on tumor cell growth are controversial. Here, we, from the view of bone marrow MSC-derived exosomes, study the molecular mechanism of MSCs on the growth of human osteosarcoma and human gastric cancer cells. Methods: MSCs derived from human bone marrow (hBMSCs) were isolated and cultured in complete DMEM/F12 supplemented with $10 \%$ exosome-depleted fetal bovine serum and $1 \%$ penicillin-streptomycin, cell culture supernatants containing exosomes were harvested and exosome purification was performed by ultracentrifugation. Osteosarcoma (MG63) and gastric cancer (SGC7901) cells, respectively, were treated with hBMSC-derived exosomes in the presence or absence of a small molecule inhibitor of Hedgehog pathway. Cell viability was measured by transwell invasion assay, scratch migration assay and CCK-8 test. The expression of the signaling molecules Smoothened, Patched-1, Gli1 and the ligand Shh were tested by western blot and RT-PCR. Results: In this study, we found that hBMSC-derived exosomes promoted MG63 and SGC7901 cell growth through the activation of Hedgehog signaling pathway. Inhibition of Hedgehog signaling pathway significantly suppressed the process of hBMSC-derived exosomes on tumor growth. Conclusion: Our findings demonstrated the new roles of hedgehog signaling pathway in the hBMSCs-derived exosomes induced tumor progression.
\end{abstract}

\section{Introduction}

(C) 2017 The Author(s)

Published by S. Karger AG, Basel

Mesenchymal stem cells (MSCs), also called Mesenchymal stromal cells, are nonhematopoietic, adherent fibroblast-like cells with innate ability for self-renewal, immune 
modulation and potential for multilineage differentiation [1-3]. Although MSCs primarily reside in the bone marrow [4,5], they are also found in placenta tissue, umbilical cord blood, adipose tissue, and in many other organs, where they are involved in maintenance and regeneration of surrounded tissues [6,7]. Whether MSCs from different sources can be regarded as the same cell type and whether surrounded microenvironments may affect their phenotype and function are still debating $[8,9]$. It has been reported that MSCs home to sites of tumor microenvironments where they participate in the formation of the tumor microenvironment and to interact with cancer cells $[10,11]$. For these reasons, MSCs can be considered as potential targets for cancer therapy [12-14]. In addition, MSCs homing to tumors not only provide the microenvironment for tumor cells, but also promote tumor growth and metastasis [15-17], although anti-tumor activities have also been reported underscoring MSC's pleiotropic properties [18-20]. However the exact mechanism remains unclear.

Exosomes are 40-100 $\mathrm{nm}$ diameter small vesicles that are secreted in the extracellular milieu by various cell types, including stem cells [21]. Exosomes are packaged with proteins, lipids and nucleic acids such as mRNAs, microRNAs (miRNAs), long non-coding RNAs (lncRNAs), genomic DNA, cDNA, and mitochondrial DNA (mtDNA), which could be used as cancer biomarker [22, 23]. Exosomes play an important role in cell-to-cell communication. They can be either taken up by neighboring cells or carried to distant sites via biological fluids and may therefore induce the phenotypic modifications in recipient cells [24, 25]. The possible mechanisms by which MSC-derived exosomes affect tumor initiation and progression have been explored. De Boeck et al. reported that MSCs promote colorectal cancer progression through paracrine neuregulin 1/HER3 signaling [26]. Zhu et al. regarded that exosomes from human adipose-derived MSCs promote migration through Wnt signaling pathway in a breast cancer cell model [27]. It has been studied that exosomes play an important role in Hedgehog pathway transporting and gradient formation [28], The activation of hedgehog signaling pathway has been attributed in a variety of human cancer, including medulloblastomas, basal cell carcinomas, gastrointestinal, leukemia, breast, lung, ovarian, and prostate cancer [29]. In addition, ligand Shh, Patch, Gli1 and Smoothened, as key molecules in the Hedgehog signaling pathway, are responsible for transduction of the intracellular signal to the nucleus and activity of downstream Hedgehog target genes [30].

To optimally understand and exploit the paracrine effects of MSC-derived exosomes on tumor progression, we therefore isolated exosomes from human bone marrow derived MSCs (hBMSCs) by monolayer culture, and investigated the effects of hBMSC-exosomes on tumor cell growth through hedgehog signaling pathway.

\section{Materials and Methods}

\section{Cell culture}

hBMSCs were isolated and cultured as previously reported [31]. All patients agreed voluntarily to participate in the study which was approved by the ethics committee of Lanzhou university second hospital (Lanzhou, china). After isolation, hBMSCs were cultured in complete DMEM/F12 supplemented with 10\% exosome-depleted fetal bovine serum and 1\% penicillin-streptomycin. Exosomes in fetal bovine serum were depleted by ultracentrifugation. Resuspended hBMSCs were plated in $25 \mathrm{~cm} 2$ culture flask at a density of $5 \times 105$ and incubated at $37^{\circ} \mathrm{C}$ in a humidified environment containing $5 \%$ CO2.When wall-attached hBMSCs reached $80 \%$ confluence, culture supernatants from hBMSCs was harvested and hBMSCs were expanded. The 3rd passage was collected for in-vitro phenotype analysis. Cellular surface antigens were examined with flow-cytometry of human hBMSCs positive for CD29, CD44, andCD105 and negative for CD45 and HLADR, as previously described [32]. Human osteosarcoma MG63 cells and human gastric cancer SGC7901 were purchased from Cell Bank, Chi Scientific, Inc. MG63 was cultured in MEM and SGC7901 was cultured in complete DMEM/F12 supplemented with 10\% fetal bovine serum, 1\% penicillin-streptomycin. All cells cultured in an incubator with a humidify atmosphere of $5 \% \mathrm{CO}_{2}$ at $37^{\circ} \mathrm{C}$.

\section{KARGER}




\section{Cellular Physiology Cell Physiol Biochem 2017;42:2242-2254 \begin{tabular}{l|l|l} 
and Biochemistry Publisned onlIne: August 16, 2017 & $\begin{array}{l}\text { C } 2017 \text { The Author(s). Published by S. Karger AG, Basel } \\
\text { www.karger.com/cpb }\end{array}$ \\
\hline
\end{tabular}}

\section{Isolation of exosomes}

The exosome-depleted fetal bovine serum for hBMSCs culture and cell culture supernatants containing exosomes were harvested and the exosomes purification by ultracentrifugation using a Ti70 rotor (optima L-100 XP Ultracentrifuge, Beckman Coulter, Brea, CA, USA). When the hBMSCs reached $80 \%-90 \%$ confluence, they were cultured for another $48 \mathrm{~h}$ and then the supernatants containing exosomes were purified according to the exosome extraction protocol [33]. In brief, cell culture supernatants were centrifuged at $300 \times \mathrm{g}$ for $10 \mathrm{~min}$ to remove cells, $2000 \times \mathrm{g}$ for $10 \mathrm{~min}$ to remove dead cells, and then 10 , $000 \times \mathrm{g}$ for $30 \mathrm{~min}$ to remove cell debris, and the supernatant was kept for the next step ultracentrifugation. After the two 100, $000 \times \mathrm{g}$ ultracentrifugations for 70min, pellets (exosomes) are kept, and supernatants are discarded. All centrifugations should be performed at $4^{\circ} \mathrm{C}$. The aliquots were passed through $0.22-\mu \mathrm{m}$ filters, the pellet was carefully resuspended in $200 \mu \mathrm{l}$ PBS and used immediately or stored at $-80{ }^{\circ} \mathrm{C}$.

\section{Transmission electron microscopy}

The methods of fix exosomes on electron-microscope grid have been described previously [33]. In brief, deposit $5 \mu \mathrm{l}$ purified exosomes on formvar-carbon coated grid. Prepare three grids for each exosome preparation. Cover and let the membranes adsorb for $20 \mathrm{~min}$ in a dry environment. After adsorption, the samples were washed with $100 \mu \mathrm{l}$ drops of PBS and transfer the grids to a $50 \mu$ drop of $1 \%$ glutaraldehyde for $5 \mathrm{~min}$. The grids were washed seven times with a $100 \mu \mathrm{l}$ drop of distilled water and let grids stand for 2 min. Repeat seven times for a total of eight water washes. Grids were dried and observed by transmission electron microscopy (FEI) at $200 \mathrm{kV}$. The images were captured using TIA software.

\section{Fluorescent labeling and confocal microscopy}

For exosome uptake studies, exosomes were labeled using the PKH26 red fluorescence cell linker kit as previously described [34]. Briefly, 15 $\mu$ g exosomes diluted in $100 \mu \mathrm{l}$ PBS were added to $1 \mathrm{ml}$ Diluent C. In parallel, $2 \mu \mathrm{l}$ PKH26 dye was added to $1 \mathrm{ml}$ Diluent $\mathrm{C}$ and incubated with the exosome solution for 4 minutes at room temperature. To bind excess dye, $2 \mathrm{ml} 1 \%$ bovine serum albumin/PBS was added. The labeled exosomes were harvested at 100, $000 \times \mathrm{g}$ for 80 minutes, and the exosomes pellet was suspended with $10 \mu \mathrm{l}$ PBS and used for further uptake experiments. MG63 and SGC7901 cells were previously cultured to $70 \%$ confluency in a 12-well plate and the medium was replaced with DMEM/F12 containing the labeled exosomes. After 24 hours incubation, MG63 and SGC7901 cells were washed by PBS for two times and fixed in 4\% paraformaldehyde for 20 minutes respectively. The cells nuclei was labeled by 4',6-diamidino-2phenylindole (DAPI) and imaged under Nikon Eclipse 80i confocal fluorescence microscopy.

\section{Cell viability assay}

Cell growth was determined by the CCK-8 assay. MG63 and SGC7901 were respectively co-cultured with different concentrations of exosomes $(0,200,400$ and $800 \mu \mathrm{g} / \mathrm{ml})$ and exosomes $(400 \mu \mathrm{g} / \mathrm{ml})$ with different concentrations of GANT- $61(0,5,10,20 \mu \mathrm{M})$ in a 96-well plates at $3 \times 103$ cells per well, Cells treated with an equal volume of exosome-depleted medium served as controls. Cell viability was measured at 24,48 and $72 \mathrm{~h}$ after exosomes and GANT-61 treatment. The cell viability was expressed as optical density (OD). The OD was measured at $540 \mathrm{~nm}$ using a microplate reader. The data are presented as the means \pm SD.

\section{Scratch migration assay}

Scratch migration assay was performed as previously described [35]. Briefly, MG63 and SGC-7901 were plated in a 12 -well plate at $1 \times 105$ cells per well and incubated at $37^{\circ} \mathrm{C}$ in a humidified environment containing 5\% CO2. When cells were grown to $90 \%$ confluence, a scratch is made through the confluent monolayer, using a sterile $10 \mu \mathrm{l}$ plastic micropipette tip, washed twice with PBS, and replaced in media added exosomes $(400 \mu \mathrm{g} / \mathrm{ml})$ with or without GANT-61 $(10 \mu \mathrm{M})$, Cells treated with an equal volume of conditional medium served as controls. Cancer cells migrate in to the scratch area as single cells from the confluent sides. The width of the scratch gap is viewed at different time periods $(0,24,48$ hours) under the microscope.

Transwell invasion assay

For invasion assay, we firstly prepared for matrigel coated membrane in the upper chamber. Each chamber was precoated with $40 \mu$ diluted matrigel/well overnight before seeding cells and then cancer 


\section{Cellular Physiology Cell Physiol Biochem 2017;42:2242-2254

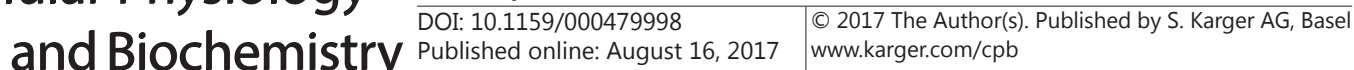 \\ Qi et al.: hBMSCs-Derived Exosomes Promote Tumor Growth}

cells were plated at a density of $7 \times 10^{4}$ cells for MG63 and $1 \times 10^{5}$ cells for SGC7901 in the upper chamber of $6.5 \mathrm{~mm}$ transwell with matrigel coated membrane (24-well insert; pore size, $8 \mu \mathrm{m}$; Corning Costar). Cancer cells were treated with exosomes $(400 \mu \mathrm{g} / \mathrm{ml})$ or treated with exosomes $(400 \mu \mathrm{g} / \mathrm{ml})$ and GANT-61 $(10 \mu \mathrm{M})$.

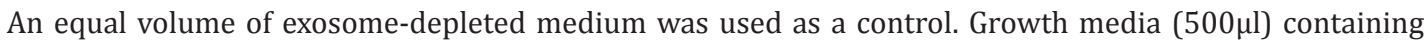
$10 \%$ FBS was added in the lower chamber of the transwell as a chemo-attractant. After a $24 \mathrm{~h}$ incubation period at $37^{\circ} \mathrm{C}, 5 \% \mathrm{CO}_{2}$, Invaded cancer cells in the lower chamber were fixed in ethanol for 15 min and stained with $0.1 \%$ crystal violet. The number of cells invading through the membrane was counted under a light microscope(20X, three random fields per well).

\section{Western blot analysis}

To identify the individual proteins in exosomes, the protein concentrations were quantified by BCA protein assay kit (Beyotime Biotechnology,China).A total of $50 \mu$ g of exosomal protein were loaded and separated on $10 \%$ SDS-PAGE, then transferred onto PVDF membranes. The membranes were incubated with the followed primary mouse monoclonal unconjugated antibodies against Hsp70, CD63 followed by incubation with secondary antibodies.

For western blot analysis of the effect of BMSC-exosomes and Hedgehog signaling pathway inhibitor GANT-61 on cancer cell growth, MG63 and SGC-7901 cells, treated with or without exosomes $(400 \mu \mathrm{g} / \mathrm{ml})$ and $10 \mu \mathrm{M}$ GANT-61 for various time points, were cultured in 6-well plates. At the end of incubation period, cancer cells from each group were lysed and prepared using RIPA buffer. Proteins were detected using specific antibodies anti-Smoothened, anti-Patched/PTCH1, anti-Gli1 and anti-Sonic hedgehog (Abcam, Inc. Shanghai, China). GAPDH was used as a loading control.

\section{Real-time quantitative PCR}

To confirm the gene array analyses, qRT-PCR was performed as previously described [36]. To detect changes in gene expression in the MG63 and SGC-7901 cells after BMSC-exosomes treatment or coimplantation with GANT-61, cells were seeded at $2 \times 105$ cells/well in 6-well plates and incubated at $37^{\circ} \mathrm{C}$ to allow cell attachment. After 24 hours, the cells were treated with exosomes $(400 \mu \mathrm{g} / \mathrm{ml}$ for $24 \mathrm{~h})$, and co-implantation with GANT-61 (10 $\mu \mathrm{M}$ for $24 \mathrm{~h})$. Cells cultured in an equal volume of exosome-free medium served as controls. After incubation, the cells were harvested. Total RNA was extracted using the Trizol reagent. Real-time PCR assays were performed in accordance with the manufacturer's instructions, using an ABI 7500 Sequence Detection System. Equal quantities of cDNA template were used for PCR with primers to generate specific products, The following PCR primers were used:

Gli1 (5'-GGCAGCACTGAAGACCTCTC- 3', 5'-ATTGGCCGGAGTTGATGTAG-3')

Patched1 (5'-TCATTAATCCCAGCGCTTTC-3', 5'-CTTTGTCGTGGACCCATTCT-3')

Shh (5'-GGACAAGTTGAACGCTTTGG-3', 5'-GCCCTCGTAGTGCAGAGACTC-3')

Smoothened (5'-CAACCTGTTTGCCATGTTTG-3', 5'-TTTGGCTCATCGTCACTCTG-3')

Glyceraldehyde-3-phosphate dehydrogenase (GAPDH) was used to normalize RNA inputs. HK-GAPD was used as endogenous normalization control. All assays were calculated on the basis of $\Delta \Delta \mathrm{Ct}$ method. The $\mathrm{n}$-fold change in mRNAs expression was determined according to the method of $2^{-\triangle \Delta C T}$.

\section{Statistical analyses}

The statistical analyses were performed with IBM SPSS Statistics 21 software (SPSS, Chicago, IL, USA). Differences were analyze using Student's t-test or one-way ANOVA. Data are presented as mean \pm standard deviation (SD), a value of p less than 0.05 was considered to be statistically significant.

\section{Results}

hBMSCs transfer exosomes to cancer cells

WefirstsuccessfullyisolatedMSCsderivedfrom humanbonemarrow, which exhibitedplastic adherence, grew as a fibroblast-like, spindle shaped morphology after 2-3 passages(Fig.1A), expressed CD29, CD44, and CD105 markers, while they were negative for CD45 or HLA-DR (Fig. 1B), this is consistent with the results reported in previous study [37]. Purified hBMSCexosomes from culture supernatant have been demonstrated by transmission electron mi- 


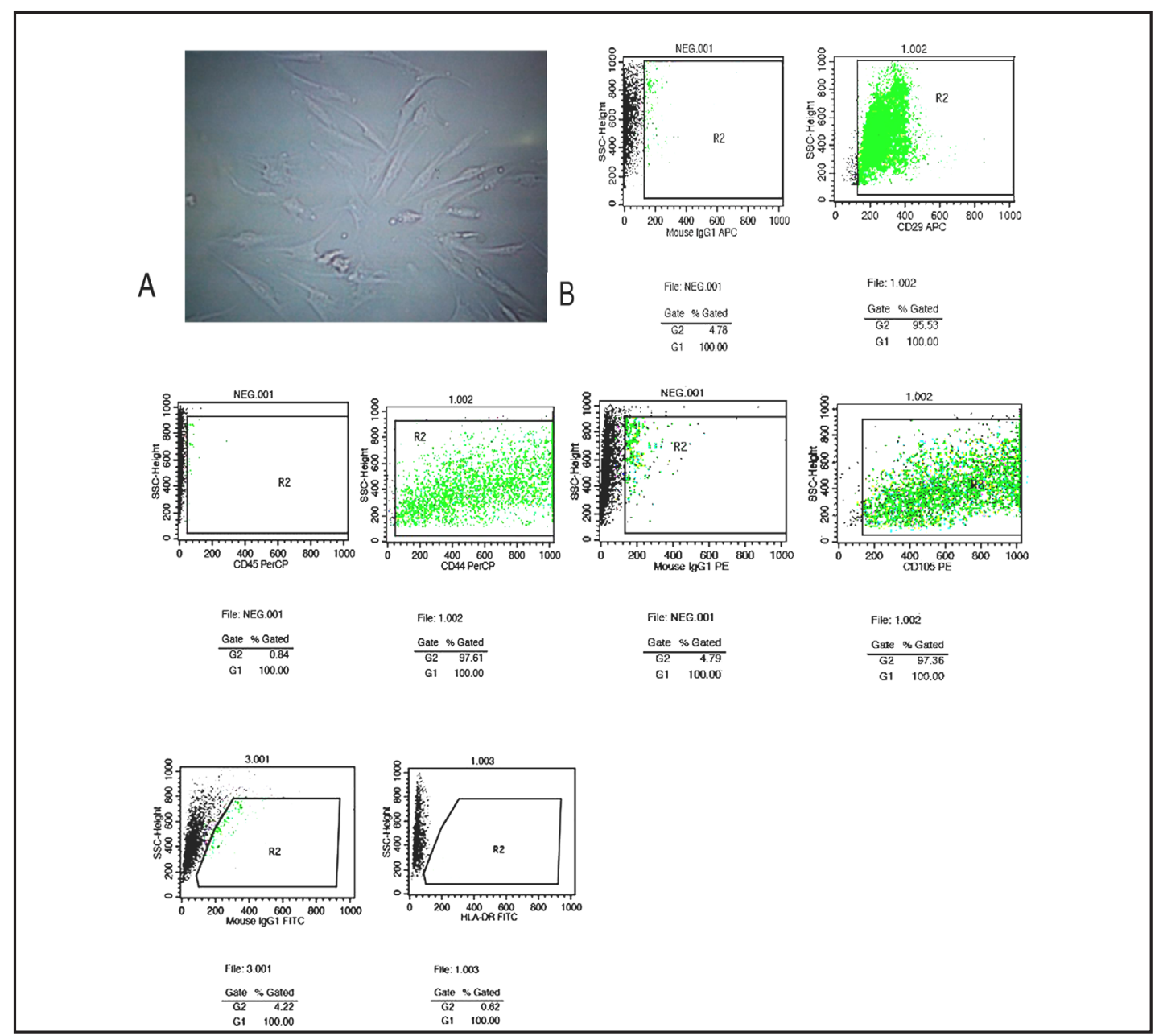

Fig. 1. Characterization of human bone marrow-derived mesenchymal stem cells. (A) The cell morphology of human bone marrow-derived MSCs was observed at 3rd passage ; grew as a fibroblast-like, spindle shaped morphology of cells were represented under light microscope. (B) Human bone marrow-derived MSCs phenotypes detected by FACS analysis, showing positive expression of CD29, CD44, and CD105 markers, while negative expression for CD45 and HLA-DR markers.

croscopy, and typical small round nanoparticles with a diameter ranging from 40 to $80 \mathrm{~nm}$ were observed (Fig. 2A). Harvested exosomes and MSCs expressed the exosomal surface markers Hsp70 and CD63, While negative in control PBS used to suspend the exosomes(Fig. 2B).

To test whether hBMSC-exosomes were internalized by MG63 and SGC7901 cells, we used the fluorescent dye, PKH26 to labeled

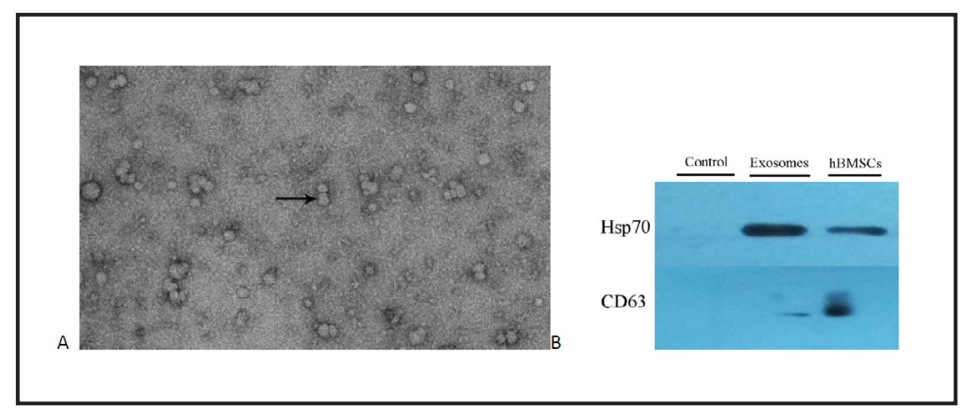

Fig. 2. Identification and characterization of exosomes secreted by human bone marrow-derived MSCs. (A) Transmission electron microscopy images of exosomes derived from MSCs revealed typical small round nanoparticles with a diameter ranging from 40 to $80 \mathrm{~nm}$. The scale bars indicate $100 \mathrm{~nm}$. (B) Detection of Hsp70 and CD63 expression in hBMSC-exosomes by western blotting. 


\section{Cellular Physiology and Biochemistry Publisnea on $\begin{aligned} & \text { DOI: 10.1159/000479998 } \\ & \text { (c) } 2017 \text { The Author(s). Published by S. Karger AG, Basel } \\ & \text { www.karger.com/cpb }\end{aligned}$ \\ Qi et al.: hBMSCs-Derived Exosomes Promote Tumor Growth}

Fig. 3. Uptake of hBMSC-exosomes by MG63 and SGC7901 cells. MSC-derived exosomes were labeled with PKH26 (red) for 4 minutes at room temperature $(\mathrm{B}, \mathrm{H})$, exosomefree supernatant was also dyed by PKH26 as a negative control (E,K). MG63 and SGC7901 cells were incubated with absence (control) or presence of labeled exosomes for 24 hours, MG63 and SGC7901 cells were stained using DAPI (A,D,G,J). PKH26-labelled exosomes have been internalized by MG63 and SGC7901 cells imaging with confocal fluorescence microscopy(original magnification, $\times 100)(C, I)$.

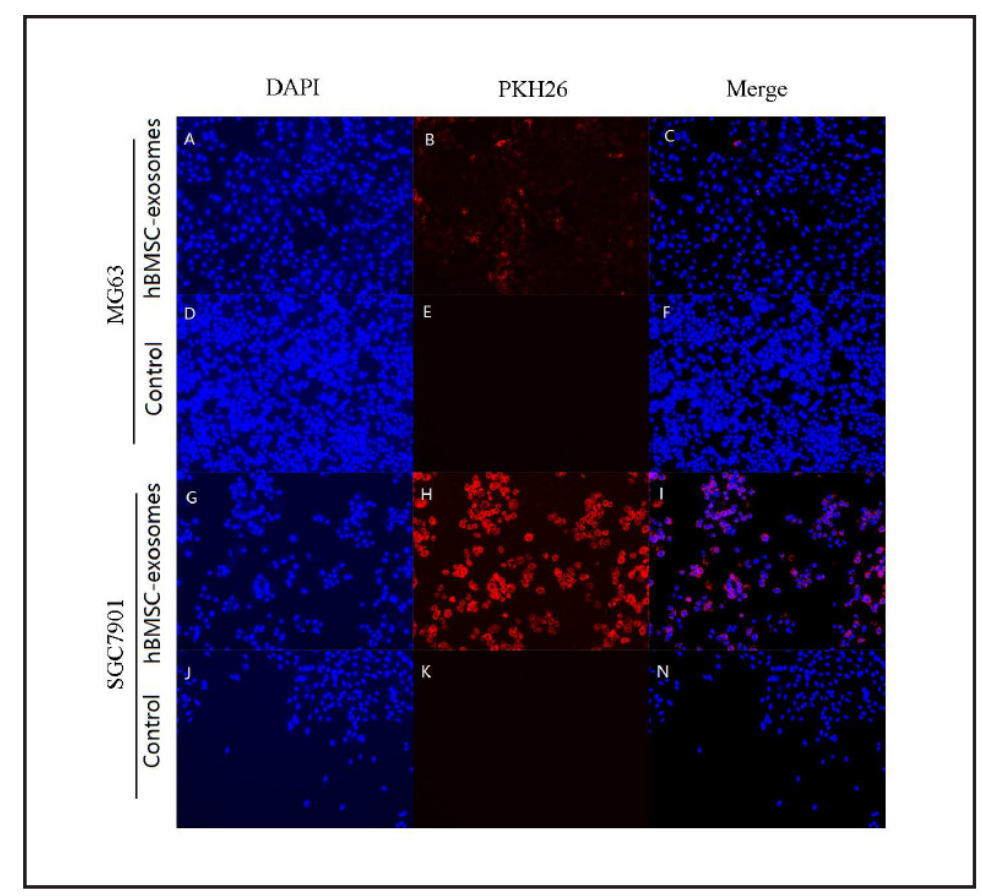

exosome, and cell nuclei were dyed by DAPI, then the exosomes and cells were incubated for 2 hours at $37^{\circ} \mathrm{C}$ with $5 \% \mathrm{CO} 2$. After incubation, we can see that the more will be intensity of red color- as there are more exosomes left, whereas the less will be intensity of red color - as there are less exosomes left. Under the confocal laser microscopy, we observed exosomes were internalized by MG63 and SGC7901 cells. For excluding the PKH26dye contamination in MG63 and SGC7901 cells, exosome-free supernatant was also dyed by PKH26 and was treated in the same way as exosomes and considered a negative control. No red fluorescence was detected when the MG63 and SGC7901 cells were treated with this control medium(Fig. $3)$.

hBMSC-derived exosomes increased cancer cell migration and promoted tumor growth through Hedgehog signaling pathway

To identify whether hBMSC-derived exosomes promoted MG63 and SGC7901 cells migration, we performed a transwell invasion assay, after incubation with $400 \mu \mathrm{g} / \mathrm{ml} \mathrm{hBMSC}$ exosomes for 24 hours, we found that human osteosarcoma MG63 cells and gastric cancer SGC7901 cells exhibited an enhanced migratory capacity after treatment with hBMSC-exosomes. However, this migratory capacity can be blocked by targeting the Hedgehog pathway with GANT-61. For excluding the effect of culture medium on MG63 and SGC7901, we added the culture medium as control group. As expected, the migration capacity of MG63 and SGC7901 cells treated with culture medium without exosomes was decreased. As shown in Fig. 4A. To further confirm this result, we performed a scratch assay to assess the migratory capacity of cells, MG63 and SGC7901 cells treated with $400 \mu \mathrm{g} / \mathrm{ml} \mathrm{hBMSC}$-exosomes migrated nearly $100 \%$ of the scratch within $48 \mathrm{~h}$, while cells treated with both $400 \mu \mathrm{g} / \mathrm{ml}$ hBMSC-exosomes and 10 $\mu \mathrm{M}$ GANT-61 failed to close the scratch after 48hours. MG63 and SGC7901 cells treated with exosome-free medium had respectively migrated $70 \%$ and $60 \%$ of the scratch after 48 hours incubation, which produced similar results with transwell invasion assay (Fig. 4B).

To investigate whether hBMSC-derived exosomes can promote MG63 and SGC7901 cells growth, we performed a CCK-8 assay. MG63 and SGC7901cells were respectively co-cultured with different concentrations of exosomes $(0,200,400 \mathrm{and} 800 \mu \mathrm{g} / \mathrm{ml})$ and exosomes $(400 \mu \mathrm{g} /$ $\mathrm{ml})$ with different concentrations of GANT-61 $(0,5,10,20 \mu \mathrm{M})$ in a 96-well plates. Cell viability was measured at 24, 48 and $72 \mathrm{~h}$ after exosomes and GANT-61 treatment. The CCK-8 assay 


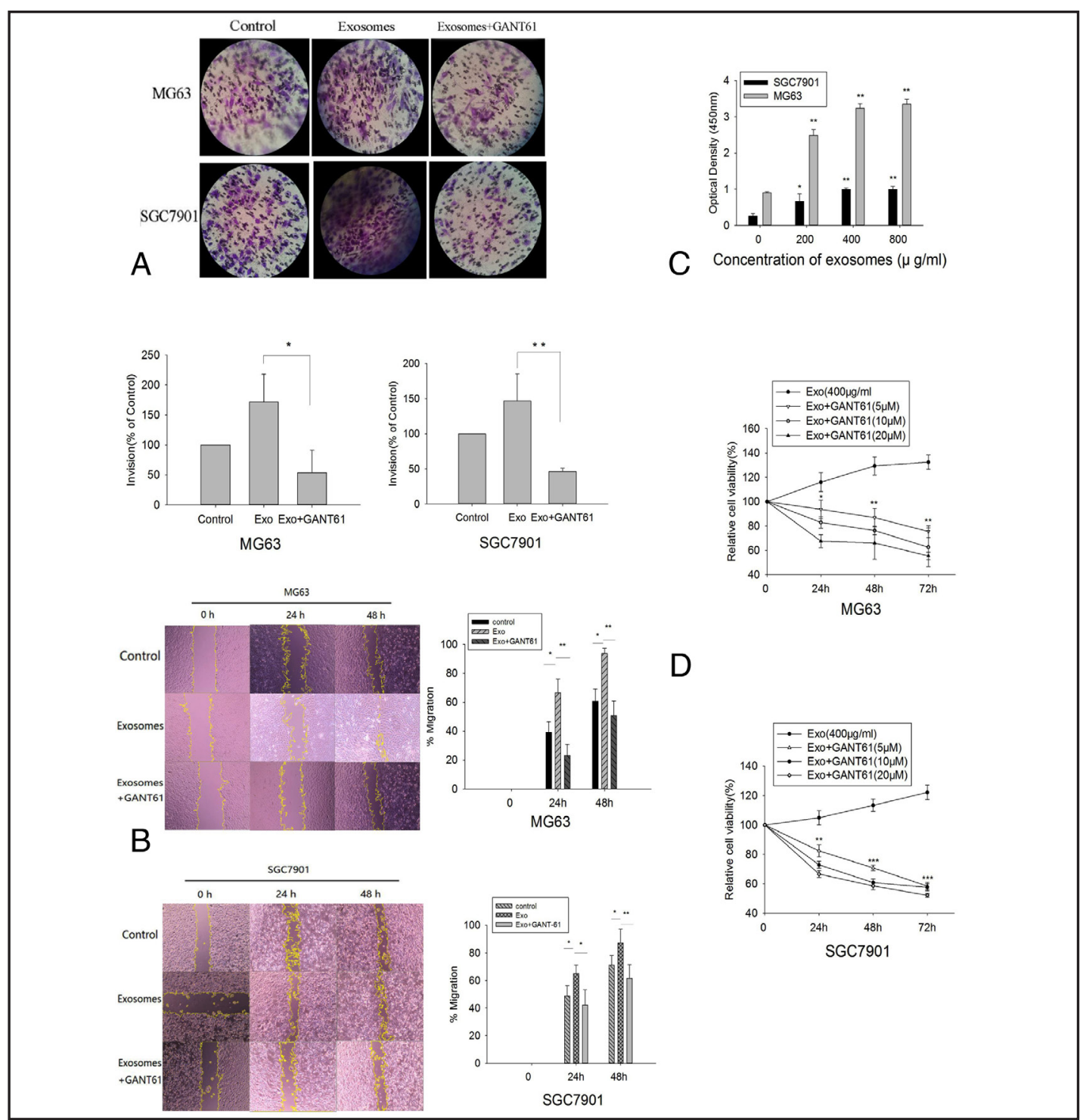

Fig. 4. hBMSC-exosomes induce viability and proliferation in MG63 and SGC7901 cells. (A) an amounts of MG63 cells and SGC7901 cells were respectively added to the upper chamber of transwell with matrigel coated membrane. Cancer cells were treated with exosomes $(400 \mu \mathrm{g} / \mathrm{ml})$ or treated with exosomes $(400 \mu \mathrm{g} /$ $\mathrm{ml}$ ) and GANT-61(10 $\mu \mathrm{M})$, an equal volume of exosome-depleted medium was used as a control. After 24 hours the number of cells migrated to the lower chamber of the $8 \mu \mathrm{m}$ pore-sized membrane were analyzed by taking photos and counting the number of cells per visual field. $\mathrm{n}=3$ per group; ${ }^{*} \mathrm{P}<0.05,{ }^{* *} \mathrm{P}<0.01$. (B) Scratch migration assay test of interfering hBMSC-exosomes group, interfering GANT61 group and control group in 24 hours and 48 hours. The wound healing assay demonstrated a stronger migration ability of cells in interfering hBMSC-exosomes group. Compared with control group and interfering GANT61 group, there were significant difference in percentage of wound closed( $\mathrm{n}=3$ per group; ${ }^{*} \mathrm{P}<0.05,{ }^{* *} \mathrm{P}<0.01$ ). a weaker migration ability of cells in the blank control and GANT61 group. (C) MG63 and SGC7901 cells were respectively co-cultured with different concentrations of hBMSC-exosomes $(0,200,400$ and $800 \mu \mathrm{g} / \mathrm{ml})$ for 24 hours and then subjected to CCK-8 analyses. $\mathrm{n}=3$ per group; ${ }^{*} \mathrm{P}<0.05$, ${ }^{* *} \mathrm{P}<0.01$. (D) MG63 or SGC7901 cells in serum-free medium were treated with $400 \mu \mathrm{g} / \mathrm{ml}$ hBMSC-exosomes or hBMSC-exosomes and different concentrations of GANT-61 $(0,5,10,20 \mu \mathrm{M})$ in a 96-well plates. Cell viability was measured using CCk-8 analyses at 24,48 and 72 hours after exosomes and GANT-61 treatment. $\mathrm{n}=3$ per group; ${ }^{*} \mathrm{P}<0.05,{ }^{* *} \mathrm{P}<0.01$, $* * * \mathrm{P}<0.001$. 
Fig. 5. hBMSC-exosomes induced activation of Hedgehog signaling pathway in MG63 and SGC7901 cells. (A) Western blotting analyses of Hedgehog signaling molecules Gli1, Patched-1, Shh and Smoothened in MG63 and SGC7901 cells treated with $400 \mu \mathrm{g} /$ $\mathrm{ml}$ hBMSC-exosomes or exposed to $400 \mu \mathrm{g}$ / ml hBMSC-exosomes and $10 \mu \mathrm{M}$ GANT-61 for 24 hours. Western blot analysis showed that the expression levels of Gli1, Patched-1, Shh and Smoothened in MG63 and SGC7901 cells were upregulated by h B M S C-exo somes, while the promoting effects hBMSCderived exosomes made have been suppressed by GANT-61. Data are shown as the means \pm SD $(\mathrm{n}=3) . * \mathrm{P}$ $<0.05, * * \mathrm{P}<0.01$. (B) MG63 and SGC-7901 cells were treated with $400 \mu \mathrm{g} / \mathrm{ml}$ BMSC-

exosomes or exposed to $400 \mu \mathrm{g} / \mathrm{ml}$ BMSC-exosomes and 10 $\mu \mathrm{M}$ GANT-61 for 24 hours and mRNA expression levels of Gli1, Patched-1, Shh and Smoothened were detected by real-time PCR.GAPDH was used as the internal control.Data are shown as the means \pm SD $(n=3) . * P<0.05,{ }^{* *} \mathrm{P}<0.01$.

showed that hBMSC-derived exosomes increased proliferation of both MG63 and SGC7901 cells in a dose-dependent manner at 24h (Fig.4C). However, in the GANT-61 treated groups, the promoting effects hBMSC-derived exosomes made have been suppressed by GANT-61 (Fig.4D). Therefore, it is suggested that hBMSC-derived exosomes increased cancer cells MG63 and SGC7901 growth through Hedgehog signaling pathway.

hBMSC-derived exosomes activate the Hedgehog signaling pathway in recipient osteosarcoma and gastric cancer cells line.

To further confirm the mechanisms by which hBMSC-exosomes promoted MG63 cells growth and migration, MG63 cells were treated with $400 \mu \mathrm{g} / \mathrm{ml} \mathrm{hBMSC}$-exosomes and exposed to both $400 \mu \mathrm{g} / \mathrm{ml}$ hBMSC-exosomes and $10 \mu \mathrm{M}$ GANT-61. After $24 \mathrm{~h}$ incubation, the whole cell lysates were subjected to western blotting. We observed that hBMSC-exosomes upregulated the Hedgehog signaling pathway in MG63 cells, consistent expression of 
Qi et al.: hBMSCs-Derived Exosomes Promote Tumor Growth

components of Hedgehog signaling pathway including the signaling molecules Smoothened, Patched-1, Gli1 and the ligand Shh. While in GANT-61 treated sample, We found a down regulated expression of Hedgehog signaling markers(Fig.5A). To further confirm that the correlation of hBMSC-derived exosomes with Hedgehog signaling pathway in the progress of cancer cells, we also employed gastric cancer cell line, SGC7901, to produce the similar results(Fig. 5A). Cancer cell lines were stimulated with hBMSC-derived exosomes for $24 \mathrm{~h}$ in the presence or absence of GANT-61, RT-PCR was subsequently conducted to observe the effects of hBMSC-exosomes and GANT61 on hedgehog pathway components in the cancer cell lines. In MG63 and SGC7901 cells, the expression of Gli1, Patched-1, Shh and Smoothened were significantly higher when cancer cells were cultured with hBMSCs-exosomes than when they were cultured on exosome-free medium. Furthermore, when GANT-61 was added to hBMSCs-exosomes, the transcripts tested (Gli1, Patched-1, Shh and Smoothened) more than 2-fold down regulation (Fig. 5B).

These results clearly demonstrate hBMSC-exosomes activate the Hedgehog signaling pathway in recipient human osteosarcoma cells and gastric cancer cells, and transcripts involved in hedgehog pathway shuttled by hBMSC-exosomes.

\section{Discussion}

In recent years, accumulating evidence indicates that MSCs play an important role on the initiation, progression and metastasis of certain tumor types, and it is believed that paracrine factors secreted by MSCs may be involved in these responses [25, 38]. Exosomes, as paracrine factors, carry enormous populations of bioactive molecules, transfer their contents to neighboring tumor cells and induce the phenotypic modifications in recipient cells $[25,39]$.

Even though the research of the interaction between hBMSC-exosomes and tumor growth has become a hot focus in recent years, however the effects of hBMSC-exosomes on the initiation and progression of tumors remains relatively unexplored. Several studies have showed that hBMSC-exosomes contribute to tumor initiation, proliferation and metastasis $[27,38]$. Whereas other reports have studied that hBMSC-exosomes inhibit tumor growth and angiogenesis $[18,20]$. To examine the exact effects of hBMSC-exosomes on tumor growth, this study examined the signaling pathway of exosomes derived from MSCs isolated from human bone marrow tissue to understand the potential molecular mechanism on cancer initiation and progression. We found that hBMSC-exosomes act as paracrine factors for reactivation of Hedgehog signaling pathway in cancer cells, suggesting that Hedgehog signaling pathway play an important role in cancer proliferation and metastasis. Exosomes, acting as exogenous factors, might have stimulated endogenous expression of intrinsic molecules of Hedgehog signaling pathway and activation of intracellular events of this pathway, as indicated by the expression of Shh ligand, Gli1, Ptch1 and Smo transcripts. Interestingly, in this study we found that the stimulatory effects of MSC-derived exosomes on cancer progression are markedly different in different cancer types. Compared with osteosarcoma cells, gastric cancer cells appear to be more sensitive to exosomes in terms of invasion and proliferation. Also, gastric cancer cells are more sensitive to inhibitory treatment, which can be important in therapeutic point of view. Consistent with invasive behavior, the expression of Hedgehog signaling molecules also seems to be more active in gastric cancer cells.

Recent report also show exosomes have been investigated as potential mediators of hedgehog signaling during development [28]. Exosomes have been implicated in the secretion, diffusion and signal transduction of the class of lipid-modified ligand, those of the Hedgehog family of secreted proteins [40]. Gradilla et al. regarded a functional Hedgehog associated to heterogeneous exosomes, either originated from exosomes or/and directly shedding from the plasma membrane of cytonemes, and that are essential for Hedgehog gradient formation [28]. The Hedgehog pathway was initially recognized for its role in embryonic 


\section{Cellular Physiology Cell Physiol Biochem 2017;42:2242-2254 \begin{tabular}{ll|l} 
DOI: 10.1159/000479998 & and Biochemistry \\
Published onnine; August 16, 2017 & $\begin{array}{l}\text { O 2017 The Author(s). Published by S. Karger AG, Basel } \\
\text { www.karger.com/cpb }\end{array}$ \\
\cline { 2 - 3 }
\end{tabular} \\ Qi et al.: hBMSCs-Derived Exosomes Promote Tumor Growth}

cell growth and differentiation and is involved in stem cell renewal, tissue regeneration, and tissue homeostasis [41]. It has also been found that Hedgehog signaling pathway was aberrantly activated which has been associated with initiation, proliferation, differentiation, migration of cell in several malignancies, including osteosarcoma cancer, gastric cancer, and so forth [42-44]. Activation of the canonical Hedgehog signaling cascade is mediated by three secreted ligands-Sonic Hedgehog (Shh), Indian Hedgehog (Ihh), and Desert Hedgehog (Dhh) and trans-membrane receptor Patched (Ptch), this activates another trans-membrane signaling molecule smoothened(Smo)[45]. Subsequently Smo signaling triggers the final mediator of hedgehog signaling, the activation of glioma-associated oncogene (Gli) family of transcription factors, Activation of the Gli proteins stimulates the transcription of hedgehog pathway target genes, including Gli1, which further amplifies the initial hedgehog signal,Gli2 and Ptch [46]. Blockage of Hedgehog signaling pathway has been proved to inhibit tumor initiation, progression and metastasis [47]. Cyclopamine, specifically binds and inhibits Smo receptor, is the first known inhibitor of the Hedgehog pathway. However, cyclopamine were not so effective for various cancer types in which Hedgehog ligand over-expression is considered to drive caner growth [48]. A small molecule inhibitor of Gli1 and Gli2, GANT61, was recently identified, acts in the nucleus to blocked Gli1-DNA binding and shows a high specificity for Hedgehog signaling [49]. Based on the above notions, in this study, we applied hBMSC-exosomes to treated different cancer cell lines. We found that these exosomes can be taken up by cancer cells. This leads to cancer cells proliferation and invasion and leads to consistent expression of various components of Hedgehog signaling pathway. To further investigated the potential involved signaling pathways of hBMSC-exosomes on tumor growth, then we used Shh/Gli antagonist, GANT61, to treat cancer cells and found that targeting Shh/Gli signaling effectively reduces hMSC-exosomes properties.

\section{Conclusion}

Our current findings for the first time demonstrated that exosomes secreted by hBMSCs have the ability to promote tumor growth through the activation of Hedgehog signaling pathway. Our findings provide new evidence of the way in which hMSCs participate in tumor progression. Thus, these findings may be of importance while modulating hedgehog signaling could be considered as a therapeutic intervention to reduce osteosarcoma and gastric cancer progression.

\section{Acknowledgements}

This work was supported by International Science and Technology Cooperation Program of China (Grant No.2015DFA31650) and supported by The National Natural Science Foundation of China (No. 81572437).

\section{Disclosure Statement}

None.

\section{References}

1 Mendez-Ferrer S, Michurina TV, Ferraro F, Mazloom AR, Macarthur BD, Lira SA, Scadden DT, Ma'ayan A, Enikolopov GN, Frenette PS: Mesenchymal and haematopoietic stem cells form a unique bone marrow niche. Nature 2010;466:829-834. 


\section{Cellular Physiology Cell Physiol Biochem 2017;42:2242-2254

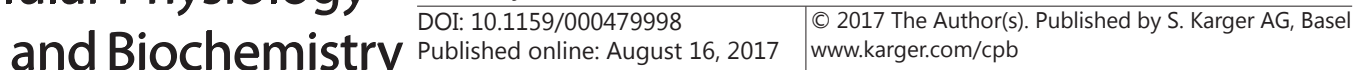

2 Pittenger MF, Mackay AM, Beck SC, Jaiswal RK, Douglas R, Mosca JD, Moorman MA, Simonetti DW, Craig S, Marshak DR: Multilineage potential of adult human mesenchymal stem cells. Science 1999;284:143-147.

-3 Salem HK, Thiemermann C: Mesenchymal stromal cells: current understanding and clinical status. Stem Cells 2010;28:585-596.

4 Johnson A, Dorshkind K: Stromal cells in myeloid and lymphoid long-term bone marrow cultures can support multiple hemopoietic lineages and modulate their production of hemopoietic growth factors. Blood 1986;68:1348-1354.

$>5$ Prockop DJ: Marrow stromal cells as stem cells for nonhematopoietic tissues. Science 1997;276:71-74. Campagnoli C, Roberts IA, Kumar S, Bennett PR, Bellantuono I, Fisk NM: Identification of mesenchymal stem/progenitor cells in human first-trimester fetal blood, liver, and bone marrow. Blood 2001;98:23962402.

7 Lee RH, Kim B, Choi I, Kim H, Choi HS, Suh K, Bae YC, Jung JS: Characterization and expression analysis of mesenchymal stem cells from human bone marrow and adipose tissue. Cell Physiol Biochem 2004;14:311324.

8 Al-Nbaheen M, Vishnubalaji R, Ali D, Bouslimi A, Al-Jassir F, Megges M, Prigione A, Adjaye J, Kassem M, Aldahmash A: Human stromal (mesenchymal) stem cells from bone marrow, adipose tissue and skin exhibit differences in molecular phenotype and differentiation potential. Stem Cell Rev 2013;9:32-43.

-9 Bianco P, Cao X, Frenette PS, Mao JJ, Robey PG, Simmons PJ, Wang CY: The meaning, the sense and the significance: translating the science of mesenchymal stem cells into medicine. Nat Med 2013;19:35-42.

10 Karp JM, Leng Teo GS: Mesenchymal stem cell homing: the devil is in the details. Cell Stem Cell 2009;4:206216.

11 Roorda BD, ter Elst A, Kamps WA, de Bont ES: Bone marrow-derived cells and tumor growth: contribution of bone marrow-derived cells to tumor micro-environments with special focus on mesenchymal stem cells. Crit Rev Oncol Hematol 2009;69:187-198.

$\checkmark 12$ Loebinger MR, Eddaoudi A, Davies D, Janes SM: Mesenchymal stem cell delivery of TRAIL can eliminate metastatic cancer. Cancer Res 2009;69:4134-4142.

13 Pascucci L, Cocce V, Bonomi A, Ami D, Ceccarelli P, Ciusani E, Vigano L, Locatelli A, Sisto F, Doglia SM, Parati E, Bernardo ME, Muraca M, Alessandri G, Bondiolotti G, Pessina A: Paclitaxel is incorporated by mesenchymal stromal cells and released in exosomes that inhibit in vitro tumor growth: a new approach for drug delivery. J Control Release 2014;192:262-270.

14 Roger M, Clavreul A, Venier-Julienne MC, Passirani C, Sindji L, Schiller P, Montero-Menei C, Menei P: Mesenchymal stem cells as cellular vehicles for delivery of nanoparticles to brain tumors. Biomaterials 2010;31:8393-8401.

15 Galie M, Konstantinidou G, Peroni D, Scambi I, Marchini C, Lisi V, Krampera M, Magnani P, Merigo F, Montani M, Boschi F, Marzola P, Orru R, Farace P, Sbarbati A, Amici A: Mesenchymal stem cells share molecular signature with mesenchymal tumor cells and favor early tumor growth in syngeneic mice. Oncogene 2008;27:2542-2551.

16 Karnoub AE, Dash AB, Vo AP, Sullivan A, Brooks MW, Bell GW, Richardson AL, Polyak K, Tubo R, Weinberg RA: Mesenchymal stem cells within tumour stroma promote breast cancer metastasis. Nature 2007;449:557-563.

17 Shinagawa K, Kitadai Y, Tanaka M, Sumida T, Kodama M, Higashi Y, Tanaka S, Yasui W, Chayama K: Mesenchymal stem cells enhance growth and metastasis of colon cancer. Int J Cancer 2010;127:2323-2333.

$>18$ Bruno S, Collino F, Deregibus MC, Grange C, Tetta C, Camussi G: Microvesicles derived from human bone marrow mesenchymal stem cells inhibit tumor growth. Stem Cells Dev 2013;22:758-771.

19 Han I, Yun M, Kim EO, Kim B, Jung MH, Kim SH: Umbilical cord tissue-derived mesenchymal stem cells induce apoptosis in PC-3 prostate cancer cells through activation of JNK and downregulation of PI3K/AKT signaling. Stem Cell Res Ther 2014;5:54.

20 Lee JK, Park SR, Jung BK, Jeon YK, Lee YS, Kim MK, Kim YG, Jang JY, Kim CW: Exosomes derived from mesenchymal stem cells suppress angiogenesis by down-regulating VEGF expression in breast cancer cells. PLoS One 2013;8:e84256.

21 Nawaz M, Fatima F, Vallabhaneni KC, Penfornis P, Valadi H, Ekstrom K, Kholia S, Whitt JD, Fernandes JD, Pochampally R, Squire JA, Camussi G: Extracellular Vesicles: Evolving Factors in Stem Cell Biology. Stem Cells Int 2016;2016:1073140. 


\section{Cellular Physiology Cell Physiol Biochem 2017;42:2242-2254 \begin{tabular}{c|c|c|} 
DOI: 10.1159/000479998 & Cond Biochemistry & 2017 The Author(s). Published by S. Karger AG, Basel \\
www.karger.com/cpb
\end{tabular}

-22 Fatima F, Nawaz M: Vesiculated Long Non-Coding RNAs: Offshore Packages Deciphering Trans-Regulation between Cells, Cancer Progression and Resistance to Therapies. Non-Coding RNA 2017;3:1-23.

-23 Nawaz M, Camussi G, Valadi H, Nazarenko I, Ekstrom K, Wang X, Principe S, Shah N, Ashraf NM, Fatima F, Neder L, Kislinger T: The emerging role of extracellular vesicles as biomarkers for urogenital cancers. Nat Rev Urol 2014;11:688-701.

24 Tan M, Yan HB, Li JN, Li WK, Fu YY, Chen W, Zhou Z: Thrombin Stimulated Platelet-Derived Exosomes Inhibit Platelet-Derived Growth Factor Receptor-Beta Expression in Vascular Smooth Muscle Cells. Cell Physiol Biochem 2016;38:2348-2365.

-25 Camussi G, Deregibus MC, Bruno S, Cantaluppi V, Biancone L: Exosomes/microvesicles as a mechanism of cell-to-cell communication. Kidney Int 2010;78:838-848.

-26 De Boeck A, Pauwels P, Hensen K, Rummens JL, Westbroek W, Hendrix A, Maynard D, Denys H, Lambein K, Braems G, Gespach C, Bracke M, De Wever O: Bone marrow-derived mesenchymal stem cells promote colorectal cancer progression through paracrine neuregulin 1/HER3 signalling. Gut 2013;62:550-560.

27 Zhu W, Huang L, Li Y, Zhang X, Gu J, Yan Y, Xu X, Wang M, Qian H, Xu W: Exosomes derived from human bone marrow mesenchymal stem cells promote tumor growth in vivo. Cancer Lett 2012;315:28-37.

28 Gradilla AC, Gonzalez E, Seijo I, Andres G, Bischoff M, Gonzalez-Mendez L, Sanchez V, Callejo A, Ibanez C, Guerra M, Ortigao-Farias JR, Sutherland JD, Gonzalez M, Barrio R, Falcon-Perez JM, Guerrero I: Exosomes as Hedgehog carriers in cytoneme-mediated transport and secretion. Nat Commun 2014;5:5649.

29 Yang L, Xie G, Fan Q, Xie J: Activation of the hedgehog-signaling pathway in human cancer and the clinical implications. Oncogene 2010;29:469-481.

30 Zhao L, Yu Y, Deng C: Protein and mRNA expression of Shh, Smo and Gli1 and inhibition by cyclopamine in hepatocytes of rats with chronic fluorosis. Toxicol Lett 2014;225:318-324.

-31 Teng X, Chen L, Chen W, Yang J, Yang Z, Shen Z: Mesenchymal Stem Cell-Derived Exosomes Improve the Microenvironment of Infarcted Myocardium Contributing to Angiogenesis and Anti-Inflammation. Cell Physiol Biochem 2015;37:2415-2424.

-32 Dudakovic A, Camilleri E, Riester SM, Lewallen EA, Kvasha S, Chen X, Radel DJ, Anderson JM, Nair AA, Evans JM, Krych AJ, Smith J, Deyle DR, Stein JL, Stein GS, Im HJ, Cool SM, Westendorf JJ, Kakar S, Dietz AB, van Wijnen AJ: High-resolution molecular validation of self-renewal and spontaneous differentiation in clinicalgrade adipose-tissue derived human mesenchymal stem cells. J Cell Biochem 2014;115:1816-1828.

33 Thery C, Amigorena S, Raposo G, Clayton A: Isolation and characterization of exosomes from cell culture supernatants and biological fluids. Curr Protoc Cell Biol 2006; Chapter 3:Unit 322.

34 Bang C, Batkai S, Dangwal S, Gupta SK, Foinquinos A, Holzmann A, Just A, Remke J, Zimmer K, Zeug A, Ponimaskin E, Schmiedl A, Yin X, Mayr M, Halder R, Fischer A, Engelhardt S, Wei Y, Schober A, Fiedler J, Thum T: Cardiac fibroblast-derived microRNA passenger strand-enriched exosomes mediate cardiomyocyte hypertrophy. J Clin Invest 2014;124:2136-2146.

-35 Fu J, Rodova M, Roy SK, Sharma J, Singh KP, Srivastava RK, Shankar S: GANT-61 inhibits pancreatic cancer stem cell growth in vitro and in NOD/SCID/IL2R gamma null mice xenograft. Cancer Lett 2013;330:22-32.

-36 Mateescu B, Kowal EJ, van Balkom BW, Bartel S, Bhattacharyya SN, Buzas EI, Buck AH, de Candia P, Chow FW, Das S, Driedonks TA, Fernandez-Messina L, Haderk F, Hill AF, Jones JC, Van Keuren-Jensen KR, Lai CP, Lasser C, Liegro ID, Lunavat TR, Lorenowicz MJ, Maas SL, Mager I, Mittelbrunn M, Momma S, Mukherjee K, Nawaz M, Pegtel DM, Pfaffl MW, Schiffelers RM, Tahara H, Thery C, Tosar JP, Wauben MH, Witwer KW, Nolte't Hoen EN: Obstacles and opportunities in the functional analysis of extracellular vesicle RNA - an ISEV position paper. J Extracell Vesicles 2017;6:1286095.

-37 Qu M, Cui J, Zhu J, Ma Y, Yuan X, Shi J, Guo D, Li C: Bone marrow-derived mesenchymal stem cells suppress NK cell recruitment and activation in PolyI:C-induced liver injury. Biochem Biophys Res Commun 2015;466:173-179.

38 Bouffi C, Djouad F, Mathieu M, Noel D, Jorgensen C: Multipotent mesenchymal stromal cells and rheumatoid arthritis: risk or benefit? Rheumatology (Oxford) 2009;48:1185-1189.

39 Roccaro AM, Sacco A, Maiso P, Azab AK, Tai YT, Reagan M, Azab F, Flores LM, Campigotto F, Weller E, Anderson KC, Scadden DT, Ghobrial IM: BM mesenchymal stromal cell-derived exosomes facilitate multiple myeloma progression. J Clin Invest 2013;123:1542-1555.

40 McGough IJ, Vincent JP: Exosomes in developmental signalling. Development 2016;143:2482-2493.

-41 Hooper JE, Scott MP: Communicating with Hedgehogs. Nat Rev Mol Cell Biol 2005;6:306-317. 


\section{Cellular Physiology Cell Physiol Biochem 2017;42:2242-2254 \begin{tabular}{l|l|l} 
DOI: 10.1159/000479998 & & $\begin{array}{l}\text { O 2017 The Author(s). Published by S. Karger AG, Basel } \\
\text { www.karger.com/cpb }\end{array}$ \\
\hline
\end{tabular} \\ Qi et al.: hBMSCs-Derived Exosomes Promote Tumor Growth}

42 Nagao-Kitamoto H, Nagata M, Nagano S, Kitamoto S, Ishidou Y, Yamamoto T, Nakamura S, Tsuru A, Abematsu M, Fujimoto Y, Yokouchi M, Kitajima S, Yoshioka T, Maeda S, Yonezawa S, Komiya S, Setoguchi T: GLI2 is a novel therapeutic target for metastasis of osteosarcoma. Int J Cancer 2015;136:1276-1284.

43 Lee SJ, Do IG, Lee J, Kim KM, Jang J, Sohn I, Kang WK: Gastric cancer (GC) patients with hedgehog pathway activation: PTCH1 and GLI2 as independent prognostic factors. Target Oncol 2013;8:271-280.

-44 Oue T, Uehara S, Yamanaka H, Nomura M, Usui N: Hedgehog signal inhibitors suppress the invasion of human rhabdomyosarcoma cells. Pediatr Surg Int 2013;29:1153-1158.

45 Sasai N, Briscoe J: Primary cilia and graded Sonic Hedgehog signaling. Wiley Interdiscip Rev Dev Biol 2012;1:753-772.

$46 \mathrm{Ng} \mathrm{JM}$, Curran T: The Hedgehog's tale: developing strategies for targeting cancer. Nat Rev Cancer 2011;11:493-501.

47 Miyazaki Y, Matsubara S, Ding Q, Tsukasa K, Yoshimitsu M, Kosai K, Takao S: Efficient elimination of pancreatic cancer stem cells by hedgehog/GLI inhibitor GANT61 in combination with mTOR inhibition. Mol Cancer 2016;15:49.

48 Amakye D, Jagani Z, Dorsch M: Unraveling the therapeutic potential of the Hedgehog pathway in cancer. Nat Med 2013;19:1410-1422.

49 Agyeman A, Jha BK, Mazumdar T, Houghton JA: Mode and specificity of binding of the small molecule GANT61 to GLI determines inhibition of GLI-DNA binding. Oncotarget 2014;5:4492-4503. 